\title{
Efficacy of prophylactic splenectomy for proximal advanced gastric cancer invading greater curvature
}

\author{
Yu Ohkura*, Shusuke Haruta, Junichi Shindoh, Tsuyoshi Tanaka, Masaki Ueno and Harushi Udagawa
}

\begin{abstract}
Background: For proximal gastric cancer invading the greater curvature, concomitant splenectomy is frequently performed to secure the clearance of lymph node metastases. However, prognostic impact of prophylactic splenectomy remains unclear. The aim of this study was to clarify the oncological significance of prophylactic splenectomy for advanced proximal gastric cancer invading the greater curvature.

Methods: Retrospective review of 108 patients who underwent total or subtotal gastrectomy for advanced proximal gastric cancer involving the greater curvature was performed. Short-term and long-term outcomes were compared between the patients who underwent splenectomy $(n=63)$ and those who did not $(n=45)$.

Results: Patients who underwent splenectomy showed higher amount of blood loss (538 vs. $450 \mathrm{~mL}, p=0.016$ ) and morbidity rate (30.2 vs. $13.3, p=0.041)$ compared with those who did not undergo splenectomy. In particular, pancreas-related complications were frequently observed among patients who received splenectomy (17.4 vs. 0\%, $p=0.003)$. However, no significant improvement of long-term outcomes were confirmed in the cases with splenectomy (5-year recurrence-free rate, 60.2 vs. $67.3 \% ; p=0.609$ and 5 -year overall survival rates, 63.7 vs. $73.6 \% ; p$ $=0.769$ ). On the other hand, splenectomy was correlated with marginally better survival in patients with Borrmann type 1 or 2 gastric cancer $(p=0.072)$.
\end{abstract}

Conclusions: For advanced proximal gastric cancer involving the greater curvature, prophylactic splenectomy may have no significant prognostic impact despite the increased morbidity rate after surgery. Such surgical procedure should be avoided as long as lymph node involvement is not evident.

Keywords: Proximal gastric cancer, Prophylactic splenectomy, Greater curvature

\section{Background}

To date, concurrent splenectomy or distal pancreatectomy has been performed in selected cases with advanced gastric cancer to secure the clearance of potential nodal involvement at the splenic hilum or along the splenic artery. However, several recent retrospective studies have reported negative outcomes in prophylactic splenectomy and there have been discussions on the necessity of splenectomy for advanced gastric cancer [1-4].

\footnotetext{
* Correspondence: yu.ohkura107@gmail.com

Departments of Gastroenterological Surgery, Toranomon Hospital, 2-2-2

Toranomon, Minato-ku, Tokyo 105-8470, Japan
}

For patients with advanced gastric cancer not involving the greater curvature of the stomach, a prospective study conducted by the Japan Clinical Oncology Group (JCOG0110) has confirmed that concurrent splenectomy has no oncological advantage despite the increased morbidity [5], and prophylactic splenectomy is currently not recommended for such cases in the Japanese Gastric Cancer Treatment Guidelines [6]. However, for advanced gastric cancer involving the greater curvature, concurrent splenectomy remains a standard procedure despite that no solid evidence has been available. Therefore, this study sought to clarify the prognostic impact of splenectomy for patients with proximal advanced gastric cancer involving the greater curvature of the stomach. 


\section{Methods}

\section{Study population}

Initial cohort included 1309 patients who underwent total or subtotal gastrectomy for advanced proximal gastric carcinoma invading greater curvature at the Department of Gastroenterological Surgery, Toranomon Hospital, between January 1975 and December 2015. Among these, 108 patients were selected according to the following inclusion criteria: histopathologically proven adenocarcinoma, T2-4 in the upper $1 / 3$ of the stomach invading the greater curvature, no gross nodal metastasis at the splenic hilum or along the splenic artery, no invasion to the spleen or the pancreas, and no evidence of distant metastases or peritoneal dissemination (both in macroscopic observation and peritoneal lavage). The definition of clinical lymph node-positive was enlarged lymph node ( $\geqq 8 \mathrm{~mm}$ in the minor axis or $\geqq 10 \mathrm{~mm}$ in the major axis) by contrast-enhanced abdominal computed tomography. The JCOG 0110 excluded Borrmann type 4 because of their aggressive malignant behavior. On the other hand, we included Borrmann type 4 because this type is thought to be associated with higher rate of peritoneal dissemination due to aggressive invasion of cancer cells to the gastric wall and it is a very important point that we should resect or preserve the spleen for these patients who had type 4 tumor. In the past report, a type 5 gastric cancer contained various types of tumors, from low-grade tumor to a high-grade tumor. However, the type 5 tumor generally has a large tumor diameter, high lymph node metastasis rate, and deeply invasive tumor. And also, these tumors has high rate of vascular invasion and high histological malignancy grade; therefore, Borrmann type 5 tumors were grouped with Borrmann types 3 and $4[7,8]$.

Then, the 108 patients were divided into two groups according to the concurrent splenectomy: the splenectomy group $(n=63)$ and spleen preservation group $(n=$ $45)$, and clinical outcomes were compared.

\section{Surgery}

D2 lymphadenectomy was routinely performed with total or subtotal gastrectomy for each patient. In the splenectomy group, lymphadenectomy along the splenic artery (No.11p and 11d lymph nodes) was completely performed with mobilizing the tail of the pancreas and only the spleen was excised while preserving the pancreatic parenchyma. In the spleen preservation group, No.11p and 11d lymph nodes were dissected without mobilizing the pancreatic tail and spleen. Lymph nodes at the splenic hilum (No.10 lymph nodes) were left untouched, but were dissected if judged easily removable in lean patients. In our hospital, treatment of advanced proximal gastric cancer was total gastrectomy with simultaneous splenectomy for adequate regional lymphadenectomy, especially splenic hilar lymph nodes. However, these indications were not established and so the surgeons finally determined whether it should be performed with or without splenectomy.

Clinical stage was determined according to the Union for International Cancer Control TNM Classification of Malignant Tumors, 7th edition on pathological examination [9]. A diagnosis of postoperative complications was made when we observed adverse events that corresponded to grade 2 or greater in the Clavien-Dindo classification [10].

\section{Data analyses}

Pairwise differences of proportions and medians were analyzed by the chi-squared test, Fisher's exact test, or Mann-Whitney $U$ test, as appropiate. Cumulative overall survival rates (OS) and recurrence-free survival rates (RFS) were analyzed by the Kaplan-Meier method. All statistical analyses were performed using Statistical Package for the Social Sciences (SPSS) version 19.0J for Windows (SPSS Inc., Chicago, IL). This study was approved by the Internal Review Board of Toranomon Hospital.

\section{Results}

\section{Patient characteristics}

Table 1 shows the clinicopathological characteristics of the patients. No significant intergroup difference was observed in clinical findings such as age, sex, tumor depth, and macroscopic or histological type. Operative duration and curability of surgery did not differ between the groups, whereas the amount of blood loss was significantly higher in the splenectomy group. As for the pathological findings, lymphatic and venous invasion, nodal metastasis, and pathological stage and postoperative chemotherapy did not differ significantly between the groups. In the spleen preservation group, No.10 dissection or sampling without splenectomy was performed in 11 patients $(24 \%)$ and the median number of retrieved No.10 nodes in these patients was 3 . There were no lymph node metastases. In the splenectomy group, four patients (6\%) were histopathologically diagnosed with nodal involvement at the splenic hilum. Of these four patients, two patients developed recurrence in peritoneum and two patients have no recurrence. The mean survival time of these four patients was 62.0 months.

\section{Postoperative complications}

Table 2a compares the postoperative complication between the two groups. Splenectomy group showed higher rate of grade 2 or greater complications according to the Clavien-Dindo classification system (30.2 vs. $13.3 \%, p=0.041)$. The rate of pancreasrelated complications was particularly higher in the splenectomy group ( 17.4 vs. $0 \%, p=0.003)$, while the rates of other types of complications were almost equivalent between the groups. 
Table 1 Clinicopathological characteristics of the 102 patients

\begin{tabular}{|c|c|c|c|}
\hline & $\begin{array}{l}\text { Splenectomy } \\
(n=63)\end{array}$ & $\begin{array}{l}\text { Spleen preservation } \\
(n=45)\end{array}$ & $p$ value \\
\hline \multicolumn{4}{|l|}{ Clinical findings } \\
\hline Age, median (range) & $64.0(40-87)$ & $65.6(20-89)$ & 0.416 \\
\hline Sex & & & 0.135 \\
\hline Male & 39 & 34 & \\
\hline Female & 24 & 11 & \\
\hline Depth of invasion & & & 0.769 \\
\hline cT2 & 29 & 22 & \\
\hline cT3-4 & 34 & 23 & \\
\hline Clinical N factor & & & 0.625 \\
\hline $\mathrm{cN}(-)$ & 31 & 20 & \\
\hline $\mathrm{cN}(+)$ & 32 & 25 & \\
\hline Borrmann macroscopic type & & & 0.196 \\
\hline Type 1 or 2 & 18 & 8 & \\
\hline Type 3 , 4, or 5 & 45 & 37 & \\
\hline Histopathological type & & & 0.406 \\
\hline Intestinal & 23 & 20 & \\
\hline Diffuse & 40 & 25 & \\
\hline \multicolumn{4}{|l|}{ Operative findings } \\
\hline \multirow[t]{2}{*}{ Operative duration (min) } & 297 & 277 & 0.660 \\
\hline & $(165-440)$ & $(140-504)$ & \\
\hline \multirow[t]{2}{*}{ Blood loss (ml) } & 538 & 450 & 0.016 \\
\hline & $(152-1900)$ & $(10-1052)$ & \\
\hline Curability & & & 0.973 \\
\hline Cur A & 24 & 17 & \\
\hline Cur B & 39 & 28 & \\
\hline \multicolumn{4}{|l|}{ Pathological findings } \\
\hline Lymphatic invasion & & & 0.512 \\
\hline Negative & 16 & 9 & \\
\hline Positive & 47 & 36 & \\
\hline Venous invasion & & & 0.267 \\
\hline Negative & 10 & 11 & \\
\hline Positive & 53 & 34 & \\
\hline Lymph node metastasis & & & 0.746 \\
\hline pNO & 23 & 16 & \\
\hline pN1 & 13 & 12 & \\
\hline $\mathrm{pN} 2,3$ & 27 & 17 & \\
\hline Pathological stage & & & 0.165 \\
\hline p stage I & 9 & 2 & \\
\hline p stage $\|$ & 18 & 21 & \\
\hline p stage III & 36 & 22 & \\
\hline Postoperative chemotherapy & & & 0.388 \\
\hline Yes & 49 & 38 & \\
\hline No & 14 & 7 & \\
\hline
\end{tabular}

Table 2 Postoperative complications and recurrence rates/ patterns

\begin{tabular}{|c|c|c|c|}
\hline & $\begin{array}{l}\text { Splenectomy } \\
(n=63)\end{array}$ & $\begin{array}{l}\text { Spleen preservation } \\
(n=45)\end{array}$ & $p$ value \\
\hline \multicolumn{4}{|l|}{ (a) Postoperative complications } \\
\hline $\begin{array}{l}\text { Morbidity } \\
\text { (CD grade } 2 \text { or higher) }\end{array}$ & $19(30.2 \%)$ & $6(13.3 \%)$ & 0.041 \\
\hline Pancreatic related & 11 & 0 & 0.003 \\
\hline $\begin{array}{l}\text { (Pancreatic fistula/ } \\
\text { abdominal abscess) }\end{array}$ & $(17.4 \%)$ & (0\%) & \\
\hline lleus & 2 & 1 & 0.767 \\
\hline Anastomotic leakage & 2 & 3 & 0.395 \\
\hline Postoperative bleeding & 1 & 1 & 0.809 \\
\hline Anastomotic stenosis & 2 & 0 & 0.261 \\
\hline Other & 1 & 1 & 0.809 \\
\hline \multicolumn{4}{|l|}{ (b) Postoperative outcome } \\
\hline Number of recurrence & $22(34.9 \%)$ & $15(33.3 \%)$ & 0.864 \\
\hline $\begin{array}{l}\text { Borrmann } \\
\text { macroscopic type }\end{array}$ & & & 0.538 \\
\hline Type 1 or 2 & 4 & 4 & \\
\hline Type 3 , 4, or 5 & 18 & 11 & \\
\hline \multicolumn{4}{|l|}{ Main recurrent patterns } \\
\hline Peritoneal dissemination & $17(27.0 \%)$ & $9(20.0 \%)$ & 0.403 \\
\hline $\begin{array}{l}\text { Distant metastasis } \\
\text { (Liver, lung, abdominal wall) }\end{array}$ & $3(4.8 \%)$ & $4(8.9 \%)$ & 0.390 \\
\hline Lymph node metastasis & $2(3.2 \%)$ & $2(4.4 \%)$ & 0.731 \\
\hline
\end{tabular}

\section{Outcomes after gastrectomy}

The median follow-up period was 135 months in the splenectomy group and 189 months in the spleen preservation group $(p=0.188)$ (Kaplan-Meier estimate). Table $2 \mathrm{~b}$ shows recurrence rates and patterns, and RFS curves are shown in Fig. 1a. Five-year recurrence-free (RFS) rates did not differ significantly between the splenectomy and spleen preservation groups (60.2 vs. $67.3 \%, p=0.609)$. As for the recurrence patterns, peritoneal dissemination occurred in $28.6 \%$ of patients in the splenectomy group and $22.2 \%$ in the spleen preservation group, with no significant intergroup difference. Isolated recurrence of nodal metastasis at the splenic hilum was observed in two (4.4\%) patients in the spleen preservation group. Overall survival (OS) curves are shown in Fig. 1b. The 5-year OS was $73.6 \%$ in the spleen preservation group and $63.7 \%$ in the splenectomy group $(p=0.769)$. In a subset analysis, splenectomy was correlated with marginally better survival in patients with Borrmann type 1 or 2 gastric cancer $(p=0.072)$. No other subgroups showed potential advantage of splenectomy for OS (Fig. 2). In addition, of all 37 patients with recurrence, the rate of the peritoneal dissemination in patients with Borrmann type 1 or 2 (4 out of 8 patients; $50.0 \%$ ) was lower than in patients with Borrmann type 3, 4, or 5 ( 24 out of 29 patients; $82.6 \%$ ), but the difference between the two groups was not significant $(p=0.056)$. 

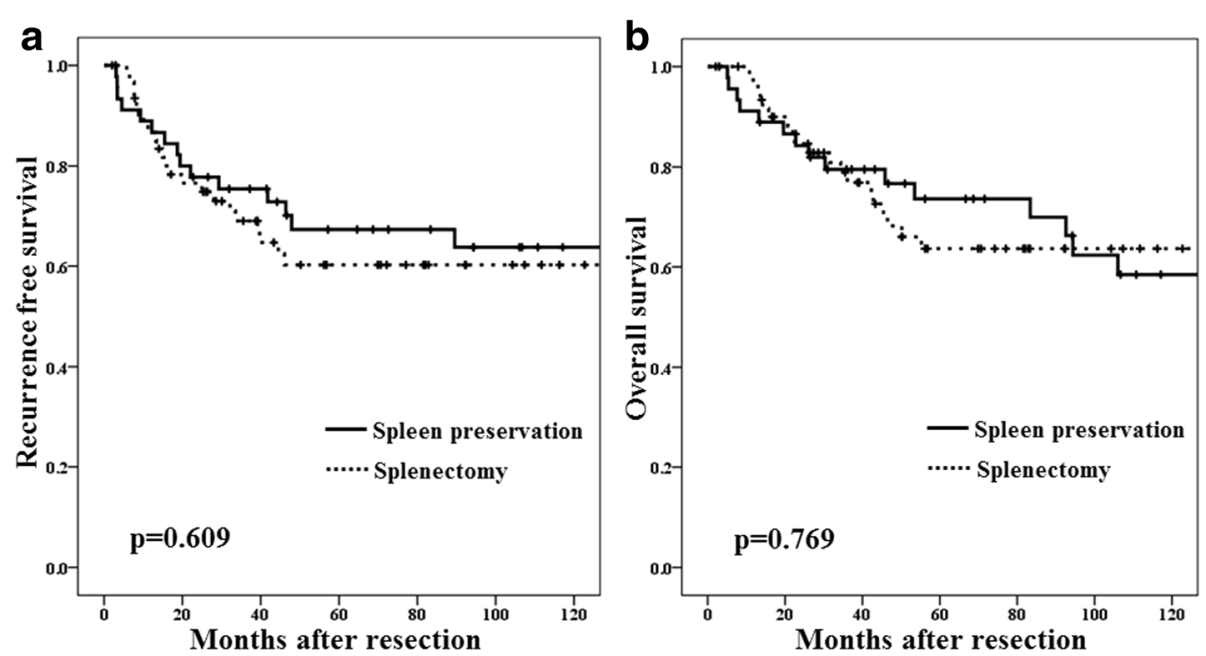

Fig. 1 a Recurrence-free survival curve. Five-year recurrence-free (RFS) rates did not differ significantly between the splenectomy and spleen preservation groups (60.2 vs. $67.3 \%, p=0.609)$. b Overall survival curve. The 5 -year OS was $73.6 \%$ in the spleen preservation group and $63.7 \%$ in the splenectomy group $(p=0.769)$

\section{Outcomes after therapeutic splenectomy}

For reference, 26 patients who were not included in this study due to therapeutic splenectomy for evident nodal involvement in No.10 or No.11p and 11d lymph nodes were additionally analyzed. Table 3 shows the clinicopathological characteristics of these patients stratified by tumor recurrence. Of the 26 patients, $17(65 \%)$ patients developed recurrence in the peritoneum $(n=16)$ or paraaortic node $(n=1)$. The median survival time of these 17 patients was 22.9 months, while the remaining 9 patients were alive without recurrence with a median survival time of 140.9 months. No evidence difference was observed in

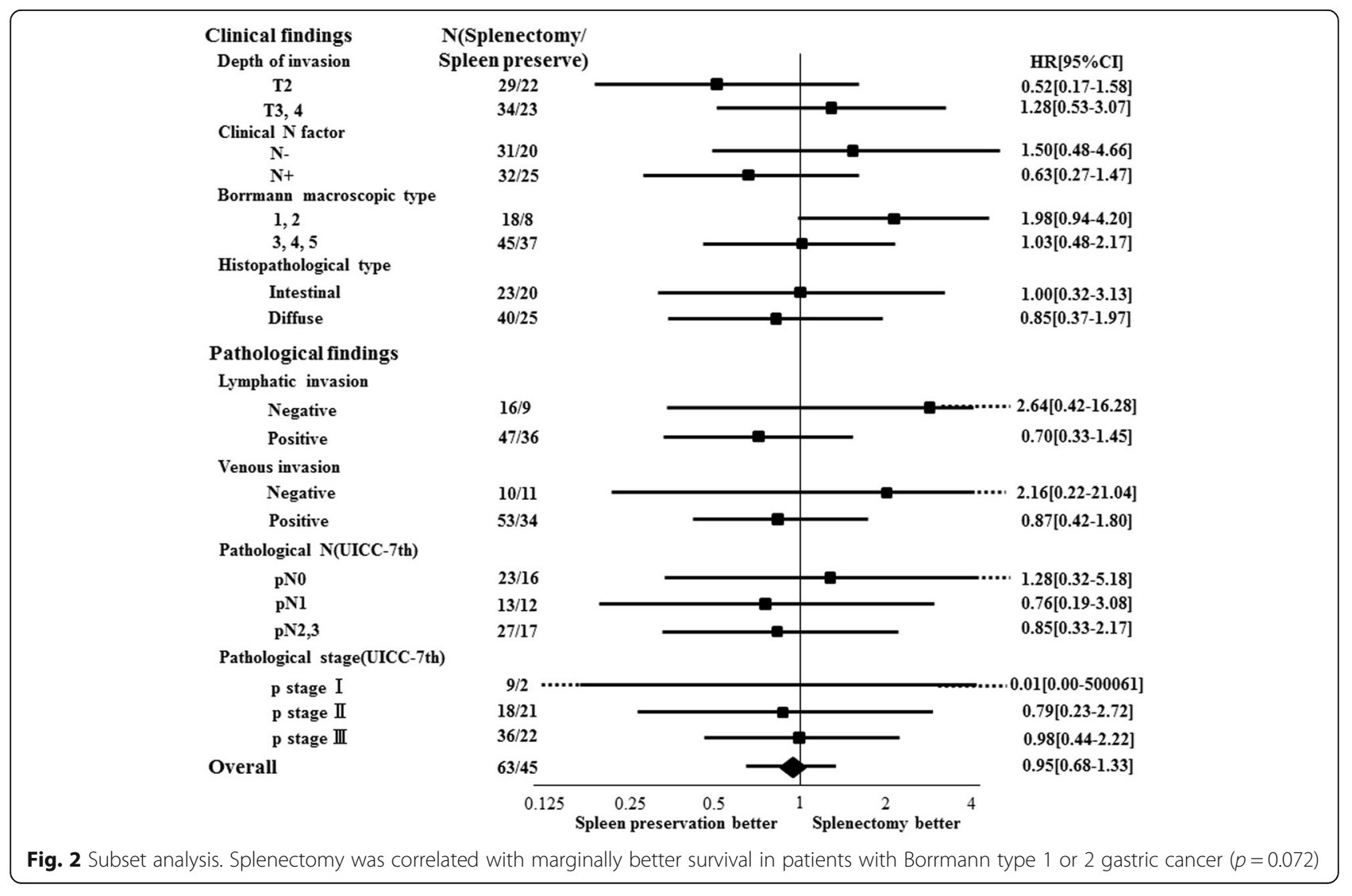


Table 3 Outcome after therapeutic splenectomy

\begin{tabular}{|c|c|c|c|}
\hline & $\begin{array}{l}\text { Recurrence } \\
(n=17)\end{array}$ & $\begin{array}{l}\text { No recurrence } \\
(n=9)\end{array}$ & $p$ value \\
\hline \multicolumn{4}{|l|}{ Clinical findings } \\
\hline Age, median (range) & $59.0(38-78)$ & $60.0(43-66)$ & 0.358 \\
\hline Sex & & & 0.484 \\
\hline Male & 7 & 5 & \\
\hline Female & 10 & 4 & \\
\hline Borrmann macroscopic type & & & 0.463 \\
\hline Type 2 & 1 & 2 & \\
\hline Type 3 & 7 & 3 & \\
\hline Type 4 or 5 & 9 & 4 & \\
\hline Histopathological type & & & 0.778 \\
\hline Intestinal & 3 & 2 & \\
\hline Diffuse & 14 & 7 & \\
\hline \multicolumn{4}{|l|}{ Operative findings } \\
\hline Operative procedure & & & 0.143 \\
\hline Splenectomy & 3 & 4 & \\
\hline Splenectomy + pancreatectomy & 14 & 5 & \\
\hline Curability & & & 0.161 \\
\hline CurA & 0 & 1 & \\
\hline CurB & 17 & 8 & \\
\hline Final stage & & & 0.359 \\
\hline Stage IIIA & 2 & 2 & \\
\hline Stage IIIB & 12 & 7 & \\
\hline Stage IIIC & 3 & 0 & \\
\hline $\begin{array}{l}\text { Lymph node metastasis } \\
\text { at the splenic hilum }\end{array}$ & 17 & 9 & \\
\hline $\begin{array}{l}\text { Lymph node metastasis } \\
\text { along the splenic artery }\end{array}$ & 5 & 4 & \\
\hline Median survival period (months) & 22.9 & 140.9 & $<0.001$ \\
\hline \multicolumn{4}{|l|}{ Main recurrent patterns } \\
\hline Peritoneal dissemination & $16(94.1 \%)$ & & \\
\hline Lymph node metastasis & $1(5.9 \%)$ & & \\
\hline
\end{tabular}

clinicopathological findings between the patients who developed recurrence and those who did not.

\section{Discussion}

Concurrent splenectomy is rarely performed in Western countries because it is reportedly associated with increased risk of postoperative complications with no survival benefits $[11,12]$. The JCOG 0110 study, a prospective randomized comparative study conducted in Japan, reported that prophylactic splenectomy has no prognostic advantage in patients with proximal advanced gastric cancer not invading the greater curvature of the stomach [5]. However, it remains inconclusive whether splenectomy is needed or not in patients with proximal advanced gastric cancer involving the greater curvature of the stomach, which would be a risk factor for nodal involvement around the splenic hilum. The current study focused on the specific population with proximal gastric cancer involving the greater curvature of the stomach and revealed that splenectomy was associated with increased risk of morbidity, and no prognostic advantage except for the specific subpopulation with Bormann type 1 or 2 tumor.

From the standpoint of safety of surgery, concurrent splenectomy was associated with significant increase in blood loss and postoperative complications in this study. The overall rate of postoperative morbidity was similar with those in the prospective JCOG0110, and the current study clarified that splenectomy was associated with significantly higher rate of pancreas-related complications $(p=0.003)$ such as pancreatic fistula/abdominal abscess $[13,14]$. Mobilization of the pancreas from the retroperitoneum and extensive lymphadenectomy along the splenic vessels may be associated with these clinical results in the splenectomy group $[15,16]$. Given that the rate of nodal involvement in the dissected lymph nodes was only $6 \%$, oncological relevance of the extensive lymphadenectomy is questionable and the current results may support the avoidance of prophylactic splenectomy even in the cases with proximal advanced gastric cancer located at the greater curvature of the stomach.

In previous retrospective studies, regardless of tumor location, the rates of 5 -year survival were $\geq 10 \%$ lower in the splenectomy group than those in the spleen preservation group [4, 17-19]. In the present study, however, no significant prognostic difference was confirmed between the splenectomy group and the spleen-preserving group in both 5 -year RFS (60.2 vs. 67.3\%) and 5-year survival rates (63.7 vs. $73.6 \%$ ). Recurrence after spleenpreserving surgery in the corresponding lymph nodes which will be excised when splenectomy is performed was observed only in two (4.4\%) patients. Furthermore, the patterns of recurrence were similar regardless of the splenectomy, with relatively high proportion of peritoneal dissemination (70-80\%) among all recurrent sites in the study group. These results may also support that prophylactic splenectomy is unnecessary for most of the cases with proximal advanced gastric cancer.

Of note, however, subset analysis stratified by the macroscopic subtype of gastric cancer showed different tendencies of prognostic advantage in splenectomy between Borrmann type 1 or 2 and Bormann type 3, 4, or 5 . The latter subtypes of gastric cancer is thought to be associated with higher rate of peritoneal dissemination due to aggressive invasion of cancer cells to the gastric wall, and as expected, there was no prognostic advantage of splenectomy due to high rate of peritoneal recurrence [20]. Meanwhile, Borrmann type 1 or 2 is mass-forming subtypes with less aggressive invasion of cancer cells into the stomach wall. The subanalysis showed that the splenectomy group for Borrmann type 1 or 2 may be 
associated with marginal prognostic advantage (Hazard ratio, 1.98; 95\% CI, 0.94-4.20; $p=0.072$ ). Actually, the two patients who had initial recurrence in the lymph node at the splenic hilum had Bormann type 1 or 2 tumor with no evidence of peritoneal dissemination.

From the practical standpoint, the current results suggest that prognostic advantage of splenectomy is relatively small in the overall population with proximal advanced gastric cancer due to aggressive patterns of recurrence including peritoneal dissemination. However, the subanalysis suggested a potentially encouraging result in a specific subpopulation with Borrmann type 1 or 2 tumors. Given that $35 \%$ of the patients with definitive findings of mesenteric infiltration or nodal metastasis at the splenic hilum or along the splenic artery (the reference cohort in this study) achieved median recurrencefree survival of 140.9 months after therapeutic lymphadenectomy; splenectomy with extensive lymphadenectomy may be effective for selected population with locally advanced cancer involving the lymph nodes. Therefore, prophylactic splenectomy with extensive lymphadenectomy remains a potentially favorable surgical approach for patients with Borrmann type 1 or 2 .

The limitation of this study includes its retrospective nature and selected population. However, perioperative management was similar during the study period, and the current study is based on a prospectively collected database for consecutive patients. Although prophylactic splenectomy showed no significant prognostic advantage in the overall population, the subpopulation with Borrmann type 1 or 2 might remain a candidate for splenectomy with marginal improvement of overall survival after splenectomy with relatively low rate of peritoneal recurrence. An external validation study using a sufficient number of patients would be needed to confirm the current observations.

\section{Conclusions}

Prophylactic splenectomy in advanced proximal gastric cancer invading the greater curvature increases postoperative complications without clearly improving RFS or OS, indicating that the procedure is not effective from a viewpoint of risk-benefit balance. However, in a subgroup of patients with less invasive macroscopic subtypes of gastric cancer, splenectomy might have a potential advantage for local control of tumor and further investigation is needed.

\section{Abbreviations}

OS: Overall survival rates; RFS: Recurrence-free survival rates

\section{Acknowledgements}

None

\section{Funding}

None declared

\section{Availability of data and materials}

Some advocates of clinical data sharing are keen for data to be shared in agreed standardized formats to facilitate its automated reuse for statistical analysis.

\section{Authors' contributions}

YO, SH, and JS designed the study and wrote the paper. YO, SH, and JS drafted the article, revised it critically for important intellectual content, and gave final approval for the content. YO, SH, JS, T, MU, and HU created the study materials or recruited the patients. All authors read and approved the final manuscript.

\section{Competing interests}

None declared

\section{Consent for publication}

Informed consent was obtained from these patients for the publication of this report.

\section{Ethics approval and consent to participate}

This study was approved by the Institutional Review Board of Toranomon Hospital.

\section{Publisher's Note}

Springer Nature remains neutral with regard to jurisdictional claims in published maps and institutional affiliations.

Received: 19 December 2016 Accepted: 16 May 2017

Published online: 25 May 2017

\section{References}

1. Griffith JP, Sue-Ling HM, Martin I, et al. Preservation of the spleen improves survival after radical surgery for gastric cancer. Gut. 1995;36:684-90.

2. Usui S, Tashiro M, Haruki S, et al. Spleen preservation versus splenectomy in laparoscopic total gastrectomy with D2 lymphadenectomy for gastric cancer: a comparison of short-term outcomes. Asian J Endosc Surg. 2016; 9(1):5-13.

3. Watanabe M, Kinoshita T, Enomoto N, et al. Clinical significance of splenic hilar dissection with splenectomy in advanced proximal gastric cancer: an analysis at a single institution in Japan. World J Surg. 2016;40(5):1165-71.

4. Maehara Y, Moriguchi S, Yoshida M, Takahashi I, Korenaga D, Sugimachi K. Splenectomy does not correlate with length of survival in patients undergoing curative total gastrectomy for gastric carcinoma. Univariate and multivariate analysis. Cancer. 1991;67:3006-9.

5. Sano T, Sasako M, Mizusawa J, Yamamoto S, Katai H, Yoshikawa T, et al. Randomized controlled trial to evaluate splenectomy in total gastrectomy for proximal gastric carcinoma. Ann Surg. 2017;265(2):277-83.

6. Japanese Gastric Cancer Association. Japanese gastric cancer treatment guidelines 2010 (ver.3). Gastric Cancer. 2011;14:113-23.

7. Sowa M, Kato Y, Nishimura M, Kubo T, Maekawa H, Umeyama K. Clinicopathological studies on type 5 carcinoma of the stomach. Jpn J Gastroenterol Surg. 1989;22(9):2230-5.

8. Kondo M, Kondo Y, Higashi T, Hasegawa N, Miyauchi A, Shiroto H, et al. Subclassification of type 5 cancer of the stomach. Jpn J Gastroenterol Surg. 1995;28(4):772-7.

9. Sobin LH, Gospodarowicz MK, Wittekind C. TNM classification of malignant tumours. 7th ed. Chichester: Wiley; 2010.

10. Dindo D, Demartines N, Clavien PA. Classification of surgical complications: a new proposal with evaluation in a cohort of 6336 patients and results of a survey. Ann Surg. 2004;240:205-13.

11. Bonenkamp JJ, Hermans J, Sasako M, van de Velde CJ, Welvaart K, Songun I, et al. Extended lymph-node dissection for gastric cancer. N Engl J Med. 1999;340(12):908-14.

12. Cuschieri A, Weeden S, Fielding J, Bancewicz J, Craven J, Joypaul V, et al. Patient survival after D1 and D2 resections for gastric cancer: long-term results of the MRC randomized surgical trial. Surgical Co-operative Group $\mathrm{Br}$ J Cancer. 1999;79(9-10):1522-30.

13. Kunisaki C, Miyata H, Konno H, Saze Z, Hirahara N, Kikuchi H, et al. Modeling preoperative risk factors for potentially lethal morbidities using a nationwide Japanese web-based database of patients undergoing distal gastrectomy for gastric cancer. Gastric Cancer. 2017;20(3):496-507. 
14. Ohkura Y, Shinohara H, Shindoh J, Haruta S, Ueno M, Sakai Y, et al. A new scoring system using preoperative factors and contour mapping for predicting postoperative complications of laparoscopic gastrectomy. Dig Surg. 2016;33(1):74-81.

15. Maruyama K, Sasako M, Kinoshita T, Sano T, Katai H, Okajima K. Pancreaspreserving total gastrectomy for proximal gastric cancer. World J Surg. 1995; 19:532-6.

16. Katai H, Yoshimura K, Fukagawa T, Sano T, Sasako M. Risk factors for pancreas related abscess after total gastrectomy. Gastric Cancer. 2005;8:137-41.

17. Brady MS, Rogatko A, Dent LL, Shiu MH. Effect of Splenectomy on morbidity and survival following curative gastrectomy for carcinoma. Arch Surg. 1991; 126:359-64.

18. Wanebo HJ, Kennedy BJ, Winchester DP, Stewart AK, Fremgen AM. Role of splenectomy in gastric cancer surgery: adverse effect of elective splenectomy on long-term survival. J Am Coll Surg. 1997;185:177-84.

19. Okajima K, Isozaki H. Splenectomy for treatment of gastric cancer: Japanese experience. World J Surg. 1995;19:537-40.

20. Li C, Oh SJ, Kim S, Hyung WJ, Yan M, Zhu ZG, et al. Macroscopic Borrmann type as a simple prognostic indicator in patients with advanced gastric cancer. Oncology. 2009;77(3-4):197-204.

Submit your next manuscript to BioMed Central and we will help you at every step:

- We accept pre-submission inquiries

- Our selector tool helps you to find the most relevant journal

- We provide round the clock customer support

- Convenient online submission

- Thorough peer review

- Inclusion in PubMed and all major indexing services

- Maximum visibility for your research

Submit your manuscript at www.biomedcentral.com/submit
Biomed Central 